penalties under the Act of Parliament, by practising as a physician for a month continuously. He might say that there was nothing at all in this case for their consideration. But admitting that there was some evidence for their consideration, still he confidently expected their verdict. He, as well as Dr. Harrison, had the greatest respect for Sir Henry Halford and other members of the College of Physicians; but sreaking of them as a body, this proceeding was illegal and disgraceful. In the first place, this Charter was granted, and the Act, if passed at all, was passed in arbitrary times - in the time of Cardinal IVolsey. By this Charter, this body was enabled to levy penalties on the subject, and this was beyond the power of the prerogative; and yet the Charter was in force for five years before the supposed Act was passed. That, however, would be a question for another day. He would not at present enter upon the question, whether this Charter and this Act could be supported, or upon any consideration of the policy of this monopoly. The only question for the $J$ ury was, whether the Act had been violated, and to prove this, they had brought forward only a single in. stance, proved by poor Emma Edwards. But in that instance Dr. Harrison had not practised as a physician, but as a surgeon. It was well known that he was a very eminent man in spinal cases, and had published a book of very high suthority on the subject. What, then, was the evidence! Nothing more than that Dr. Harrison had attended this lady for an affection of the spine, not as a physician, but as a surgeon; and this was no violation of the Act. The College had, therefore, totally failed in making out their case.

Lord TeNTerden, in putting the case to the jury, observed that the only question for their consideration was, whether the defendant had practised as a physician for any one month during the year 1327. They had nothing to do with the question as to the expediency of the charter; and with respect to the act of Parliament by which the charter was confirmed, the question which had been mooted as to that was not a fit one to be decided in that place before a single judge, but ought to be maturely considered by the whole Court. That question would probably undergo discussion in case the jury found for the plaintiffs on the question of fact as to the practising as a physician. His Lordship then recapitulated the evidence, and observed, that the defence set up to-day was somewhat at variance with the defendant's own letters to the Collece. In those letters it seemed to be conceded that he was practising as a physician, and if he had not been so practising, the question which had been agitated could not arise; for, as a surgeon, he was not required to take out a licence from the College. There was no dispute as to his right to practise as a surgeon; the only question was, whether be could practise as a physician without being licensed by the College. His first letter to Dr. Chambers referred to the circumstance of that gentleman's having declined to meet him in consultation. Now it was well known that no physician declined meeting a surgeon in consultation, and it was perfectly clear that Dr. Chambers's objection to meet Dr. Harrison was because he was practising as an unlicensed. physician. There was not one word in the defendant's letters from which it could be inferred that he was practising as a surgeon merely; on the contrary, the main object of these letters seemed to be to assert his right to practise as a physician. The jury would connect the statements in his own letters with the parole testimony given today, and recollecting that it had been proved that he had not attended the lady for a spinal complaint merely, but had written prescriptions for internal remedies in the way that a physician usually prescribed, they would then say whether it had not been made out to their satisfaction that he had practised as a physician during the period in question. If they were satisfied of that fact, their verdict must be for the plaintiffs; but if they thought that he had practised solely as a surgeon, then the defendant would be entitled to their verdict.

The $J u r y$ retired to consider their verdict, and after being absent three quarters of an hour, they found for the defendant.

AN ACCOUNT OF ANEURISMS FOLIOWING ARTERTOTOMY.

By George Bushe, II.D. of the Royal College of Surgeons in Ireland, and Assistant Surgeon of the Forces.

IN this communication, it is my object to describe the different species of aneurism which I have observed to follow arteriotomy; and, I purpose to illustrate the same with appropriate cases. The undertaking, it is hoped, will not prove unprofitable, since the subject has not yet met with that attention which it so justly merits; however, it may be necessary to apprise some of my readers, that M. Desruelles has lately written on this subject, in the Transactions of the Medical Society of Emulation atParis; but his paper, though it contains much useful matter, can in no way detract from the advantages that may accrue from the publication of the following pages; for the reader will soon learn that $I$ have described forms of the disease untouched by him, and illus- 
trated the same with instructive cases; therefore, without further prefatory remarks, I shall lay before the public what information $I$ possess on this subject.

In the second volume of Sir A. Cooper's Lectures, it is written, "I have seen several cases of temporal aneurisms from arte. riotomy in that vessel, one in MIr. Heusleigh, a medical student. I opened the sac, secured the temporal artery at its lower part, and was there obliged to secure many others entering the circumference of the suc, which had been excessively dilated." No doubt this case, in the language of Mr.J. Bell, was an anastomosing aneurism; and one, in all probability, produced by the operation of arteriotomy.

Again, if the reader will look to Mr. A. Burns' work on the head and neck, page $3 \pm 2$, he will observe a case in which the temporal artery was opened for an apoplectic affection, to which succeeded an aneurism by anastomosis, and which Mr. Burns believed existed beneath the temporal fascia before arteriotomy was performed, and was the cause of the cephalic symptoms. It is with great deference that I would oppose such high authority as Mr. Burns, but from the extract I have made from Sir $A$. Cooper's work, together with the following cases, I am led to suppose, that aneurism from anastomosis is not a very uncommon sequel of partial or total section of the temporal artery, and that, in all likelihood, Mr. Burns erred when he gave it as his opinion, that the aneurism existed beneath the temporal fascia before the performance of arteriotomy ; and that the true nature of the disease only became manifest after the division of the membrane.

CAs E 1.-On the 30 th of April, $1826, \mathrm{G}$. Graham, private in the 54 th regiment, was admitted into Fort Pitt General Hospital, in consequence of concussion of the brain, produced by a fall, sustained a few hours previously, when intoxicated. In the second stage of the disease, (as mentioned by Mr. Abernethy ;) blood was taken from his right temporal artery, but no bandage was subsequently employed, as its application produced an increase of headach and general fever. The wound in the temple did not unite, and a pulsating tumour gradually formed, which, from the 18 th to the $22 \mathrm{~d}$ of May, bled frequently and profusely, though firm pressure was steadily applied; indeed the tumour appeared to extend rapidly under this treatment. On the latter date a vertical section was made of the aneurism, and pressure re-applied; but, much to my annoyance, the progress of the disease appeared to be increased by the means adopted, and on the 26th, in consultation with Dr. Skey, deputy inspector of hospitals, and Mr. Millar, surgeon to the forces, it was determined to secure the trunk of the vessel near the root of the ear; this was accordingly executed; but we were again disappointed to find, that the steps adopted were totally ineffectual, as neither the growth of the aneurism, nor the hamorrhage from it, were suspended; the exterior of the swelling on the 15th of June, being about the size of a hen's eg.g, ulcerated in the centre, fungated more ex. ternally, and at its circumference, where the skin was entire, it possessed a purple colour, irregular surface, and cedematous feel; the whole mass being simultaneously moved with the contractions of the left side of the heart; moreover his countenance was pallid, and his frame debilitated and emaciated from the protracted stage of suffering, and repeated hamorrhages. A consultation was held, and the removal of the diseased mass recommended. Assisted by Dr. Skey, I proceeded as follows:-

Pressure being made on the carotid artery, an elliptical incision was carried round the base of the tumour, and its removal completed by dissecting from above downwards. In prosecuting this part of the operation, the knife had to be carried freely into the body of the temporal muscle, in consequence of the aneurism being lodged in it, particularly at its lower part behind the zygoma. But little blood was lost during the operation; but when the pressure was removed from the carotid, several large branches sprang in the body of the temporal muscle, one of which was secured by ligature, but the others being numerous and deep seated, the application of sponge and graduated pressure were employed to restrain the bleeding. On the third day the wound was dressed, after which it soon granulated, and rapidly healed. The morbid parts corresponded to the structure which Mr. J. Bell describes as peculiar to aneurism from anastomosis.

CAse 2.-In June,1826, - Salmon, publican, in Fort Pitt Barracks, had an apoplectic fit, for which he was blooded from the left temple, by assistant-surgeon Foid, to which, in the course of fourteen days, succeeded an aneurismal tumour, about the size of a filbert; the wound in the temple never having healed, it bled freely and re. peatedly, was of a purple colour, and attended with the peculiar doughy feel so remarkable in Graham's case; pressure was applied, but Mr. Ford informed me, that it had most manifestly exasperated the disease. I removed the tumour (which laid above the temporal fascia) without difficulty, but to restrain the hæmorrhage, I found it necessary to apply two ligatures, and fill the wound with sponge. The excised parts resembled those removed from Grabam's temple. 
CASE 3.-In Jan. 1827, Captain M., of the $3 d$ Regt. of Foot, was affected with inflammation of the iris of his right eye, for which the temporal artery was opened, but as he stated that the pain of his head was increased by the bandage, after' a few hours its application was discontinued ; the wound did not heal, and an aneurism formed, which, at the end of eight days, had acquired the size of a hazel nnt; pressure was applied, but repeated attacks of hæmorrhage ensued, and the tumour, on the thirteenth day, was as large as the segment of a walnut. An incision was then made around its base, so as to divide the superficial vessels passing into it; and, after three trunks were secured, the pressure was re-applied; but this expedient did not answer, for, on the eighteenth day, the aneurism being rather larger than that of Graham's, its remoral appeared imperative. Assisted by Mr. Fryer, assistant sulgeon, 46th Regt., I accomplished the desired object, which was rendered very difficult in consequence of the number of vessels entering its base, and the depth at which it lay beneath the zygoma, in the substance of the temporal nuscle. The bleeding vessels were so numerous, that to apply ligatures to them, at such a depth from the surface, in a narrow cavity, appeared impossible, therefore by plugying the wound with sponge, the hæmorrhage was restrained; a healthy wound followed, and in a fortnight it had skinned over. This aneurism I injected and corroded, by which means its true structure was clearly exposed.

I lave now mentioned three cases, in which anastomosing aneurisms followed the operation for arteriotomy, and from them may be deduced much useful matter. In the section of Sir A. Cooper's lectures before alluded to, it is stated,- " Aneurisms are to be prevented after arteriotomy, by the complete division of the vessel."' This opinion being derived from such high authority, carries with it much weight, therefore it is with great deference that I would oppose it; but in two of the above cases the vessel was cut across, after the desired quantity of blood had been abstracted, viz., in those of Graham and Captain M. Hence I am firmly convinced, that the means recommended by Sir A. Cooper will not prevent the formation of anastomosing aneurism, notwithstanding it will, undoubtedly, that of a species hereafter to be mentioned viz., that of the trunk itself. I cannot com prehend how a complete division of the vessel could possibly operate against the de. veloprent of a structure, consisting of a dilatation of the anastomosing vessels, though it is easy to understand the rationale of its operation, in the prevention of false aneurisms of the temporal artery; and, moreover,
$I$ am convinced, that in the most careful attempts that can be made to complete the section of the vessel, the temporal fascia will be divided, by which a communication is opened between the superficial and deepseated vessels, an event that tends to increase the malady, and render the removal of the diseased parts much more difficult. In exemplification of this, contrast the depth at which the aneurisms of Graham and Captain M. lay in the body of the temporal muscle behind the zygoma, and the supply of blood they received from the deep temporal arteries, with the superficial situation of the aneurism of Salmon, viz., external to the temporal fascia; the facility with which it was removed and the hremorrhage restrained, the deep temporal arteries being free from disease. From these facts, I cannot withhold recommending a discontinuance of the conmon practice of cutting across the vessel, when a sufficient quantity of bloood has been abstracted; for though such a proceeding will prevent the formation of aneurism in the trunk of the vessel, still, if there is a disposition to the formation of anastomosing disease, it will, in my mind, increase it, and the establishment of dilatation of the trunk itself can be prevented by the application of pressure. In the cases of Graham and Captain M., pressure was not employed after the operation of arteriotomy; but in Salmon's case, it was applied in the usual way, still it did not prevent the formation of anastomosing disease; therefore I am disposed to conclude, that in some individuals, there is, from causes yet unknown, a disposition to this peculiar morbid action which is called into existence, no matter how completely the vessel is divided, or how accurately pressure is employed.

In the three cases related after the ap. pearance of the discase in the anastomosing vessels, pressure was applied, and in all it appeared to expedite the growth of the tumours, increase the central ulceration, and finally to produce much constitutional annoyance. These effects I have observed to follow pressure, when applied to anastomosing aneurisms of spontaneous origin; and the same results have been pretty strongly hinted at by John Bell, and some other authors. 'Therefore I would recom. mend, that as soon as the disease becomes manifest, pressure should be immediately discontinued.

In the case of Captain MI., a circular incision was made around the base of the tumour, as recornmended by Sir Astley Cooper, and afterwards firm pressure wus applied; but 1 did not carry the jncision to the bone as proposed by Sir Astley, as in the case alluded to by him, the aneurism was situated on the forehead, where he had 
not to contend with deep-seated vesisels, situated in a thick muscle. The result of the attempt in the case treated by me, the reader will recollect, proved abortive; but the failure can easily be explained in this way: by the incision, the super. ficial, temporal, and frontal arteries, were only divided; and the aneurism having its supply of blood principally from the deep temporal arteries, its growth continued, because they were left undivided, hence I shall not again adopt this proceeding. But it may be asked, if the incision was carried through the body of the muscle down to the bone; would it then not have answered? In reply, I would say, that we can never judge of the extent of the base of such aneurisms, by their external appearance ; an opinion which the above cases will justify; and as, by external examination, we cannot gain knowledge of their inward extent; an incision, though carried widely round the base of such tumours, might, in all probability, pass in to the substance, thereby give rise to troublesome hæmorrhage, and an increased rate of their growth. And even if, in such cases, we could inclose the morbid parts with an incision, I should fear that the trunks of the deep temporals, would pour out blood very freely, and, in all probability, require dilatation of the wound, for the application of ligatures to stem the hrmorrhage ; and, above all, as the encircled mass could only receive blood from the bone, (a quantity small indeed,) sloughing of the diseased parts would be the consequence; a process, which, though radical in its effects, would be attended with so much irritation and delay, that $I$ cannot look upon it as a desirable curative mean.

In Graham's case, the tumour was divided throughout its vertical extent, and afterwards plugged with sponge; but the reader will recollect, that after this plan of treatment, the disease extended more rapidly than heretofore, therefore I cannot agree to the following passage in Sir A. Cooper's lectures :- "The operation best calculated to cure aneurisms of the scalp, is to cut directly across them, and to make use of pressure to stop the bleeding, to prevent the course of the blood through the swelling, and to produce adhesion of the sides of the sac."

It was stated that, in Graham's case, a ligature was applied to the trunk of the vessel, and that it did not affect the growth of the aneurism; but when we recollect that the morbid mass was fed, not only by the superficial temporal, but also by the frontal and deep temporals, its failure can be easily explained. Hence it may be unnecessary to add, that such a proceeding is not at all adapted, even to suspend the progress of such diseases.
From a consideration of what $I$ have now written, $I$ have no hesitation in recommend. ing excision, as soon after the formation of the disease as possible, as the means best calculated to establish a safe and radical cure.

The next species of aneurism, arising from arteriotomy, which $I$ shall describe, is that of the trunk of the vessel itself; a form of dis. ease of which I have seen many cases, particularly in the ophthalmic hospital of this establishment (which I had charge of, from September 1826 to May 1828). This is the form of aneurism described by Desruelles; and I can safely say that I never saw a case of this disease, where pressure was properly applied, after the closing of the wound, though the vessel was left undivided. I am particular in this statement; because Desruelles has assigned imperfect division of the ressel, as a cause of the malady. However, I must admit, that I have never observed the disease after the com. plete division of the vessel; nor is it possible to conceive how it could exist, when such a measure is alopted; but though this may be a certain preventive, still $l$ conceive it to be a bad practice, inasmuch as other means prove effectual, and are unattended with the danger that sometimes follows complete division, when there is a tendency to the formation of anastomosing aneurism. In all these cases, after the performance of arteriotomy, I have observed that the wound healed, and that it was only after the aneurism had acquired some size, that the integuments ulcerated in the site of the cicatrix, giving rise to troublesome hæmorrhage.* At one period, I was in the habit of securing the trunk of the vessel; again, of dividing the aneurism through its centre, and tying the extremities of the vessel; but more lately I have been uniformly successful by making firm pressure with a coin wrapped in old linen, and secured with a firm roller. Indeed, these aneurisms are very common, and very easily cured.

The last form of the disease, which I shall describe, is aneurismal varix, of which I have seen but the following case :-

General D., xt. 78, for some years had laboured under carcinomatous ulceration of his left eye and temple. In August, 1826, he had an apoplectic seizure, for which his right temporal artery was opened near the ear, and in consequence of the diseased condition of the left side of his head, pressure was not subsequently employed. He gradu-

* It is to be recollected, that in none of the cases of anastomosing aneurism which I have described, did the wound heal after the performance of arteriotomy. 
ally recorered from the apoplexy, and, in three months afterwards, I visited him with IIr. Sproute, surgeon of the Royal Engineers, who was his medical attendant, when we found that a regularly-formed aneurismal varix was established in the situation where the artery had been opened; but as it was not troublesome, no curative means were had recourse to. In May, 1827, he died; when, on examination, I found that a large dilated vein lay over the artery, adhered to it, and communicated with it, by a small, but well defined and direct, opening.

As I stated before, this is the only case of this form of disease that I have observed to follow arteriotomy; therefore my judgment on it cannot be very perfect. But from a consideration of the structure of the parts, $I$ conceive it may be avoided; by not opening the artery close to the ear; as in this situation the vessel has frequently in front of it large and contorted veins; and the parotid fascia, ascending over the zygoma in this situation, will bear off the pressure applied to restrain the bleeding. For $[$ believe these two circumstances favour the formation of a disease, which may be avoided, by opening the vessel where it is only covered by the skin, and comparatively unaccompanied by veins. In the above case no curative means were adopted; but if analogical reasoning be allowed, it is fair to suppose that pressure would have effected a cure.

\section{GAPINGS OF AN OYSTER.}

\section{To the Editor of $\mathrm{T}_{\mathrm{H}} \mathrm{T}$ TMEs.}

SIR,-In The Times of November 8, 1827, I endeavoured to support your previous censures upon the occasional rapacity of unworthy medical practitioners ; and while the disgraceful conduct of law-mongers is undergoing Parliamentary inquiry, I will ask the public attention to a proposal for the better regulation of the several classes of men engaged in the healing art. It seems to me that most of the contentions and abusive disputes which now dishonour the whole medical profession are occasioned by sordid passions, and that a prurient greediness of money-getting fame is the principal source of our notoriously disturbed condition.

Cnder the sanction of experience, I am convinced that the important art of healing may be assuredly ameliorated by equitable regulations, and also progressively improved by directing the activity of varied talent to right purposes.

Before the London Colleges of Physicians and Surgeons, and the Company of Apothe- caries, are condemned upon the assertions of evil-minded or envious medical demagogues, the public should be apprised of the real destinations of those institutions, and of the national services which they perform.

The division of the officers of health in to physicians, surgeons and apothecaries, is convenient, and if not invidiously defined, those several distinctions may be wisely continued; but I presently intend to suggest a more rational mole of payment, according to their respective accomplishments in learning and science, and their progres. sive attainments from experience.

I do not believe that any subversive changes in our English colleges would amend the profession or benefit the public; but a review and comparison of their several charters, by-laws, and usages, might enable ruling minds to detect many prevailing errors, and lead to combine the severalclasses of medical men under more genial com. pacts.

When the English College of Physicians was first estanlished, the chief sources of medical knowlege were derivable from the classic remains of the ancient Greeks and Romans, and consequently the Universities of Oxford and Cambridge were then the best schools for medical education; but subsequent discoveries and improvements in every elementary science have entirely superseded the semi-monastic discipline of that age; and at this time it may be truly said, that the teaching of anatomy, chymistry, therapeutics, medicine, and surgery, are better conducted under the rivalship of self-appointed lecturers, than at either : the English Lniversities.

The College of Surgeons was first chartered to supply duly qualified English surgeons for the services of the terrible wars of the 15th century, and to exclude itinerant foreigu pretenders, and ignoran $t$ quacks.

The two London Colleges are merely the constituted ordeals for examining into the competency of candidates, and for cranting diplomas, privileging their members to practise. They have never been schools for instruction, and frobably any approach to render them such would prove injurious.

The incorporation of Londion apothecaries have vacillated between the subordinate offices at first demanded of them by physicians, and the business of wholesale and retail drug merchants and medical chemists ; but their increasing ministrations as subphysicians, have rendered them so essential to the midule order of society, that the Company of Apothecaries have very properly acquired an exclusive Parliamentary power in favour of their members. Indecd, their certificates of competence from physicians who teach the art of medicine, 